Review Article

\section{The relationship between it use and aggression in Pakistani youth}

\author{
Waqar Husain ${ }^{1 *}$ and Sehrish Mobeen² \\ ${ }^{1}$ Assistant Professor, Department of Humanities, COMSATS University, Islamabad, Pakistan \\ ${ }^{2}$ Psychologist Graduated, Department of Psychology, Foundation University, Islamabad, Pakistan
}

\section{Abstract}

The use of Information Technology (IT) has made our live comfortable at present however, it has also generated certain health concerns. The disproportionate exercise of IT, with indication to accessible literature, has been consistently interrelated with psychopathological indications counting the problems of aggression as well. Although this issue was not much focused in Pakistan, this study was planned to determine the connection among the expenditure of IT and aggression in Pakistani youth. The query incorporated 200 conveniently chosen Pakistani youth between 16 to 24 years of age from 4 cities. The Aggression Scale of Buss \& Perry was used along with a demographic information questionnaire. The study was hypothesized that among Pakistani youth elevated utilization of IT would be positively correlated with higher levels of aggression. It was significantly proved by the results that elevated utilization of IT is positively and significantly correlated with aggression. The findings of this study may be helpful to psychologists, counsellors, parents and teachers in diagnosing problems of the Facebook generation.

\section{More Information}

*Address for Correspondence: Waqar Husain, Assistant Professor, Department of Humanities, COMSATS University, Islamabad, Pakistan, Tel: +92-3005960102; Email: drsukoon@gmail.com

Submitted: December 17, 2020

Approved: April 07, 2021

Published: April 08, 2021

How to cite this article: Husain W, Mobeen S The relationship between it use and aggression in Pakistani youth. Arch Psychiatr Ment Health. 2021; 5: 022-024.

DOI: 10.29328/journal.apmh.1001031

ORCiD: orcid.org/0000-0003-3047-1834

Copyright: @ 2021 Husain W, et al. This is an open access article distributed under the Creative Commons Attribution License, which permits unrestricted use, distribution, and reproduction in any medium, provided the original work is properly cited.

(4) Check for updates

(3) OPEn Access

\section{Introduction}

The positive and negative effects of Information Techno logy (IT) from traditional and psychosocial point of view has been discussed and questioned since ages. No doubt IT has brought a great change in human lives by making it more comfortable and easy. It's overuse has also resulted in an enslaved attitude and behavioral problem side by side. Despite that IT has provided the humans with diverse affirmative assistance, there are some domains which are affected globally by the excessive use of IT. Many researches picked out the negative results of IT. Persistent change in technology has continuously affected the collective socialization, communication and job interactions. Many researchers believed that IT is the main source of creating social issues and problems [1].

There are situations in which a person may experience pain and injury. This type may or may not be associated with aggression because the source of intention may not exist. Sometimes, an individual may get pain for acquiring some other purposes. Like the one who desires to print a tattoo on his body is receiving and bearing the pain by their will and acceptance [2]. The definition of aggression is a conduct or act of a person which may be harmful to others. The destruction might be substantial, emotional or social. In short the overall perspective of aggression involves a person who plan or mean to hurt a subject/target and that subject is dynamically geared to escape away from that damage [3-6].

Violent aggression is the uppermost peak of aggression. Its outcome could be more severe due to its painful effect on others. this may include rigorous harm, injury or fatality. Whereas, instrumental aggression is not intended for any injury towards others except to attain some sort of purposes and objectives. Its main concern is to sheltered oneself or to achieve any sort of remuneration [5,6]. "Information technology rage" or "technostress" [7] become visible when a person discovers his own self incompetent to transact with recent or modern technology. These situations place the person in a frustrated status ultimately diminishing the application of technology and intensifying aggression while relating or connecting with modern technology. It is an ailment of adjustment which person perceives that his capabilities are undersupplied to execute computer technology [8].

The term Electronic aggression is used when the occurrence or incident of aggression is exhibited during the use of technology. This might be bullying and harassing other person by using different techniques like by laughing at them, exasperating them, passing rude comments/remark, and spreading fabricated rumors about them [9]. Methods such as quick messages, blogs, social media, e-mail etc. are being adopted for these purposes. 
The association related to aggression and the use of technology has not been focused in the literature. The current study, therefore, was planned for exploring association between the use of IT and aggression within Pakistani youth. It was hypothesized that greater use of IT would be highly associated with greater aggression in Pakistani youth.

\section{Material and methods}

In the current study, IT use was operationally defined as the total minutes spent per day for using internet and making phone calls or text messages.

\section{Participants}

The sample of the study was collected from 4 different cities of Pakistan i.e. Islamabad, Peshawar, Jhelum and Rawalpindi. 200 participants were selected by convenient sampling technique having age ranges from 16-24.

\section{Instruments}

Demographic information questionnaire: Demographic questionnaire included the information related to age and time duration of using IT from the respondents.

The aggression questionnaire (Buss and Perry, 1992): The aggression scale [13] was used to investigate the intensity of aggression in the respondents. It has 29 items. This scale aids in observing and measuring the conducts that can cause physical or mental harm. It measures different frequencies of aggressive behaviors like verbal, physical, hostility and anger. Each item of the scale is rated on five-point scale ranging from 1 to 5. Scale's total score ranges from 29-145. Cronbach's alpha coefficient is .88. The Pearson correlation of anger subscale with physical and verbal aggression is .48 and .48 respectively. The correlation between physical aggression and verbal aggression is .45. The magnitude of the score obtained on the scale reflects the intensity of aggression and vice versa.

\section{Procedure}

The researcher visited various academic centers located in different cities of Pakistan which were conveniently selected and gather the data. Ethical principles and confidential aspects were considered properly. Statistical Package for Social Sciences (SPSS) was used for analyzing data.

\section{Results}

Table 1 indicates that Aggression Questionnaire has excellent reliability (i.e. .97) for the sample of the present study.

Table 2 reveals a highly significant and positive relationship between IT use and aggression.

Table 3 interprets the mean score of Pakistani youth on Aggression Questionnaire. It was revealed that Pakistani youth had a Very High Aggression Level.
Table 4 analyzes the difference between boys and girls on Aggression. It revealed that girls have higher levels of aggression as compared to boys.

\begin{tabular}{|c|c|c|}
\hline \multicolumn{2}{|c|}{ Table 1: Chronbach's Alpha reliability for Aggression } & Questionnaire $(\mathrm{N}=200)$ \\
\hline Scale & No of Items & Reliability \\
\hline \multicolumn{1}{|c|}{ Aggression } & 29 & .97 \\
\hline$p<.001$ & & \\
\hline
\end{tabular}

Table 2: Pearson Product Correlation coefficient for use of IT Consumption and Aggression for the sample $(\mathrm{N}=200)$

\begin{tabular}{|c|c|}
\hline & Aggression \\
\hline IT Consumption & $.614^{* * *}$ \\
\hline
\end{tabular}

Table 3: Mean and Interpretation of the overall scores of Pakistani youth on Aggression Questionnaire.

\begin{tabular}{|c|c|c|c|c|c|c|}
\hline & & $\mathbf{N}$ & M & \multicolumn{3}{|c|}{ Interpretation } \\
\hline \multicolumn{2}{|c|}{ Aggression } & 200 & 90 & \multicolumn{3}{|c|}{ Very High Aggression } \\
\hline & $\mathbf{N}$ & \multicolumn{2}{|c|}{ M } & SD & $t$ - value & $p$ - value \\
\hline Females & 100 & \multicolumn{2}{|c|}{89.98} & 4.26 & \multirow{2}{*}{14.97} & \multirow{2}{*}{.000} \\
\hline Males & 100 & \multicolumn{2}{|c|}{79.94} & 5.16 & & \\
\hline
\end{tabular}

\section{Discussion and conclusion}

The study's main focus was to identify the association between the use of IT and aggression in Pakistani youth. The study hypothesized that excessive utilization of IT would be highly associated with elevated aggression. Outcomes of the study are consistent with the hypothesis on a highly significant level.

Numerous mental and emotional problems are linked with the rigorous and severe utilization of computers [10-12]. We found that Internet was the most frequently used IT device by youth. Higher utilization of IT led towards aggressive behaviors. Internet gives accessibility to the individuals to interact and spend time with others; but this also intensifies the possibility of intimidation and aggression towards oneself or others by the social networking websites and channels [14]. Improper utilization of IT especially electronic media might lead feeling of being weak or powerless [15].

In aggression there is always the phenomenon of disproportion of supremacy between sufferer and the victimizer [16]. Unique characteristics owned by Modern technology authorize and facilitate the users by multiple perspectives, particularly in respect to aggression. As it aids the person to easily wrap up their individuality from the target. It also inhibits the target or victim to stop or finished this sort of harassment or bullying [9].

Pakistani youth would be apprehended with the results of the current study as to be cautioned in the utilization of information technology, as the inappropriate and unnecessary utilization can escort them to various mental 
and emotional problems including aggression as well. The findings of the study will be helpful to parents and instructors as well to ensure balance in the use of IT sources for academic and learning purposes. The Psychologists and counsellors shall also consider the duration and nature of IT use while diagnosing the problems of youths at present.

\section{References}

1. Hacker M, Barden R A. Technology in your world. Albany, NY, Delmar Publishers. 1987.

2. Baumeister RF. Masochism and the Self. Hillsdale, New York: Hillsdale. 1989.

3. Bushman BJ, Anderson CA. Is it time to pull the plug on hostile versus instrumental aggression dichotomy? Psychol Rev. 2001; 108: 273-279. PubMed: https://pubmed.ncbi.nlm.nih.gov/11212630/

4. Baron RA, Richardson DR. Human Aggression. New York: Plenum. 1994.

5. Berkowitz L. Pain and Aggression: some findings and implications. Motivating Emotions. 1993; 17: 277-293.

6. Bell PA, Green T, Fisher JD, Baum A. Environmental Psychology. New Jersey. 2001.

7. Fiehn B. Stressing Out: Handling Change in a Digital World. Community \& Junior College Libraries. 2010; 16: 255-258.

8. Brod C. Technostress: The Human Cost of the Computer Revolution. Reading, Mass: Addison Weslety. 1984.

9. Hertz MF, David-Ferdon C. Electronic media and youth violence: A
CDC issue brief for educators and caregivers. Atlanta, GA: Centers for Disease Control. 2008.

10. Aronsson G, Dallner M, Aborg C. Winners and losers from computerization: a study of psychological work conditions and health of Swedish State employees. Int J Human Computer Interaction. 1994; 6: 17-37.

11. Nakazawa K, Quirk MC, Chitwood RA, Watanabe M, Yeckel MF, et al. Requirement for hippocampal CA3 NMDA receptors in associative memory recall. Science. 2002; 297: 211-218. PubMed: https://pubmed.ncbi.nlm.nih.gov/12040087/

12. Korpinen LH, Pääkkönen RJ, Self report of physical symptoms associated with using mobile phones and other electrical devices. Bioelectromagnetics. 2009; 30: 431-437. PubMed: https://pubmed.ncbi.nlm.nih.gov/19399784/

13. Buss AH, Perry M. The aggression questionnaire. J Personality Social Psychol. 1999; 63: 452-459.

PubMed: https://pubmed.ncbi.nlm.nih.gov/1403624/

14. Mishna F, Khoury-Kassabri M, Gadalla T, Daciuk J. Risk factors for involvement in cyber bullying: Victims, bullies and bully-victims. Children and Youth Services Rev. 2012; 34: 63-70.

15. Warren DE, Smith-Crowe K. Deciding what's right: The role of external sanctions and embarrassment in shaping moral judgments in the workplace. Res Organizational Behavior. 2008; 28: 81-105.

16. Olweus D, Limber S, Mihalic SF. Blueprints for violence prevention, book nine: Bullying prevention program. Boulder, CO: Center for the Study and Prevention of Violence. 1999.

17. Butterfield L. Board H. Children, young people and the internet. Social Work Now. 2002; 30: 2005. 